\title{
TURISMO Y ORDENACIÓN DEL LITORAL: PRESENTACIÓN Y BALANCE DE TRES CASOS CONCLUSIONES MESA REDONDA
}

\begin{abstract}
RESUMEN
La ordenación del litoral en zonas turísticas tiene dimensiones y escalas diversas que se han venido abordando, con mayor o menor fortuna, desde la planificación territorial hasta el urbanismo municipal, y en pocos casos, supramunicipal. Por otra parte, las condiciones singulares del medio litoral plantean escenarios de crisis frente al cambio climático, sin que se activen los protocolos necesarios para abordar la excepcionalidad y las urgencias a la que nos enfrentamos.

Se defiende en esta intervención que las herramientas urbanísticas son realmente las determinantes porque inciden decisivamente en tres aspectos sustantivos del suelo: dominio, uso y plusvalía, en un contexto generalizado de propiedad privada, alto dinamismo de los usos y prácticas especulativas intensas. Seguimos en el albor de la tercera década del siglo xxi con los conceptos y herramientas creados a mediados del siglo xx en pleno franquismo (Ley de 1956) y hemos visto y vivido como el ciclo de burbuja inmobiliaria —crisis económica y social ha desnudado y mostrado su obsolescencia, y aparecen como inservibles para hacer frente a los retos actuales.

Desde la plataforma de los arquitectos urbanistas se formuló hace dos años una propuesta de regeneración/ renovación del urbanismo en España ("Ante el agotamiento de un modelo, por un urbanismo responsable", UAAU-CSCAE) donde se plantean unas bases completamente diferentes, tanto sobre la prevalencia de los derechos humanos frente a otros derechos en confrontación, la atribución pública de las plusvalías generadas por el planeamiento urbanístico y la generación de nuevas formas de planificación, gestión y control del espacio urbano y territorial más ágiles y dinámicas, más ajustadas a las necesidades y posibilidades de la gobernanza de la ciudad y del paisaje.
\end{abstract}

a Instituto iHTT, Universitat Politècnica de Catalunya. 


\title{
TOURISM AND COASTAL MANAGEMENT: PRESENTATION AND ASSESSMENT OF THREE CASES CONCLUSIONS OF THE ROUND TABLE
}

\begin{abstract}
Coastal planning in tourist areas addressed various dimensions and scales, with different results: from territorial to municipal planning and, in a few cases, also supra-communal planning. The unique conditions of the coastal environment pose emergency scenarios concerning climate change, without activating the necessary actions to address its exceptionality and emergencies.

This contribution argues that urban tools are determinants due to their impact on three main aspects of the soil: domain, use and surplus value - in a generalized context of private property, highly dynamic uses and intense speculative practices. At the beginning of the third decade of the 21 st century, we still adopt concepts and tools created in the middle of the 20th century during Francoism (Law of 1956). And we saw and lived on our skin how the cycle of real estate bubble economic and socio-economic crisis showed its obsolescence, and it appeared useless in facing current challenges.

Two years ago, a proposal for regeneration/renewal of urban planning in Spain was redacted by the platform of planning architects: "In reaction to the exhaustion of a model, for a responsible urbanism", UAAU-CSCAE. In this document, new bases are established: starting from the prevalence of human rights; passing from the public attribution of the gains generated by urban planning; and finally, focusing on the generation of new forms of planning, management and control of urban and territorial spaces, which are every day more agile and dynamic and more adapted to the needs and possibilities of city and landscape governance.
\end{abstract}

Todas las intervenciones que se han presentado en esta Jornada han abordado, desde posiciones diversas por la naturaleza de los territorios y/o por los enfoques disciplinares, la "ordenación del litoral" en relación con el turismo. La palabra "ordenación" nos remite tanto a dimensiones territoriales como urbanas del fenómeno turístico y es pertinente recordar que "el tamaño no es la escala", para comprender cuando estamos hablando de propuestas de carácter regulatorio, más o menos incisivas, o de propuestas de intervención transformadora en los espacios litorales.

También se han planteado en estas intervenciones escenarios de "emergencia", fundamentalmente de carácter ambiental y relacionados con la crisis climática global en la que estamos inmersos. La emergencia nos sitúa en escenarios de urgencia y de medidas excepcionales, aunque muchos expertos expresen que ya llegamos tarde para revertir el cambio climático. Llegar tarde parece ser una actitud aceptada frente a las emergencias que no están consideradas dentro de los protocolos de protección civil, como ha sucedido y sigue sucediendo con la denominada "emergencia habitacional", ya que en ningún caso se han activado esos protocolos u otros que fueran realmente efectivos para hacer frente a la emergencia desde la lógica de la excepcionalidad y la urgencia.

El recorrido realizado en las ponencias se ha ido moviendo de la dimensión territorial a la urbana 
a través de los instrumentos de planificación disponibles, para la ordenación territorial en los ejemplos del País Valencià y de Galicia y urbanísticos en el caso de Catalunya. Las dimensiones y dinámicas específicas del espacio litoral permiten esta diversidad de enfoques y el uso de herramientas diversas, pero quisiera poner de relieve que, al final, las urbanísticas son determinantes porque inciden en un tema clave: los usos del suelo en relación a sus transformaciones por procesos urbanizadores y/o edificatorios.

El urbanismo incide decisivamente en tres cuestiones fundamentales relacionadas con el suelo: el dominio, los usos y las plusvalías. Sobre el dominio, permite en un entorno generalizado de propiedad privada del suelo obtener suelos de propiedad pública para las necesidades del espacio urbano: calles, zonas verdes y equipamientos comunitarios. Sobre los usos del suelo, establece el contenido urbanístico de la propiedad privada, es decir, los potenciales de urbanización y edificación y los usos admisibles de suelos y techos edificables o ya edificados. Y sobre las plusvalías, el enorme efecto económico que comportan los cambios en los usos del suelo, cuando pasan de no urbanos a urbanos, los atribuye a la propiedad (abrumadoramente privada) con leves reducciones en función del criterio de una cierta "participación de la comunidad" en esas plusvalías.

Se trata de un modelo urbanístico en relación al suelo que es común en los países de base jurídica romana, pero que está muy alejado de los fundamentos y prácticas de los países de mentalidad sajona o germánica, donde la prevalencia del derecho público es la base de la práctica urbanística, a través de la legislación específica y/o a través de la fuerza inversora de la administración, sobretodo en la escala local. En los temas de ordenación del litoral, la legislación de costas sería una buena referencia para avanzar en esa lógica de prevalencia de lo público en las decisiones de ordenación y de gestión de unos suelos excepcionales y singulares sobre los que se ha ejercido y ejerce una presión especulativa desaforada, con los resultados tan empobrecidos que constatamos.

Desde la plataforma asociativa de los arquitectos urbanistas (las Agrupaciones dentro de los colegios profesionales, y la Unión de Agrupaciones en el seno del Consejo Superior de Colegios de Arquitectos), se impulsó un amplio debate sobre la necesidad de renovar el urbanismo español a partir de un diagnóstico común: la obsolescencia del modelo urbanístico establecido des de la Ley de 1956 sobre régimen del suelo y ordenación urbana, que en esencia pervive tanto en la legislación estatal actual como en las autonómicas, obsolescencia puesta dramáticamente de manifiesto (por sus consecuencias económicas y sociales) con la crisis inmobiliaria desde 2007.

De los debates realizados surgió una propuesta ratificada por unanimidad en febrero de 2016 por el Plenario de Decanos de los Colegios de Arquitectos, y que puede ser una buena base para avanzar hacia la creación de un modelo urbanístico completamente diferente al actual y que tenga la capacidad de canalizar y resolver los retos planteados ya casi en la tercera década del siglo XXI. Se puede encontrar este documento (coloquialmente llamado "declaración de Cartagena" porque fue donde cristalizó en el encuentro anual de todas las Agrupaciones de arquitectos urbanistas del año 2015). El documento está disponible en seis lenguas, las cuatro oficiales en el estado español y las dos oficiales del Consejo Europeo de Urbanistas, en https://www.cscae.com/index.php/documentos-uaau 
Un resumen muy sintético de su contenido sería, quizá a modo de preámbulo y exposición de motivos de esa nueva legislación, el siguiente:

- La prevalencia de los derechos humanos en la ciudad y específicamente los derechos a la vivienda y al hábitat urbano y a la participación en los procesos de planificación y gestión.

- Establecer la titularidad pública inicial de las plusvalías generadas a través de la decisión colectiva de planificación de los usos del suelo, con participación privada en función de su aportación real.

- Prioridad a la transformación del espacio urbanizado y construido frente al consumo de nuevos suelos, reforzando el cumplimiento de la función social de la propiedad urbana.

- Simplificación de los instrumentos para la ordenación y transformación del suelo, con herramientas flexibles y dinámicas que hagan posible la gobernanza sobre el suelo y sus usos también en ámbitos supramunicipales.

- Volver a situar la forma urbana, la arquitectura, en el centro del debate disciplinar y de las propuestas concretas en cada entorno ambiental y paisajístico. 